DOI: 10.1515/ausfm-2016-0008

\title{
Accommodating the Mess: The Politics of Appropriation in It for Others (2013)
}

\author{
Paula Blair \\ Lancaster University (UK) \\ E-mail: p.blair@lancaster.ac.uk
}

\begin{abstract}
In response to Chris Marker and Alain Resnais's collaborative meditation on art and colonialism in Statues Also Die (1953), Duncan Campbell's video installation It for Others (2013) takes a complex approach to presenting a Marxist criticism of the commoditization of art and culture. This article considers the intermedial and intertextual properties of It for Others as an example of convergence culture that transcends postmodern quotation and pastiche. While the film is apparently a bricolage of visual artefacts, it is in fact an intricately woven audiovisual essay concerned with the appropriation of not only colonized objects as its narration makes clear, but also of still images, moving images, written texts, sound samples, and the labour that produced them. The article examines how the film troubles notions of documentary realism and truth through its acts of appropriation that reflexively criticize the commercial appropriation and commoditization of artworks and histories. It also reflects on the film's Marxist approach to related issues around authorship, ownership and access to artworks, particularly in the light of the film's acknowledgement in prize culture.
\end{abstract}

Keywords: video installation, appropriation, intermediality, intertextuality, circulation.

Primarily situated in the art gallery, Duncan Campbell's films problematize the authority of documentary film and probe its relationships with time, memory and the archive. They trouble notions around indexical truth and fixed accounts of history while teasing the boundaries and functions of cinema, television, video art, performance and photography. While Bernadette (Campbell, 2008) and Make It New John (Campbell, 2009) largely consist of televisual material, they are far from being categorized as television documentaries. These art films that re-mythologize the lives of the socialist-nationalist Ulster politician Bernadette Devlin McAliskey and the American car manufacturing mogul John DeLorean - lives which in the 1960s to 1980s played out under the close scrutiny of the 
Western media - will never be shown on television even though many of their archival components have appeared in more conventional expository compilation documentaries.

In reassessing the histories of figures whose own accounts railed against populist versions, largely through the reconstitution of available resources mixed with original materials, Irish-born Campbell's films invite questions around the authorship of history and the authorship of film. They reframe and dissolve fixed borders by working with exclusions from collective memory to reevaluate historicized memories. The ways that they reveal how selectively framed images of real life can often jar with reality encourage critical thinking about the mythologization and memorialization of historical figures and events. Unlike more traditional modes of documentary, Campbell's works reflexively question their own construction using modernist techniques of fragmentation, repetition and disjunctive editing including sound montages. At a remove from the commercial cinema space, they facilitate the realignment of documentary with the early modernist cinema's potential for revolutionary politics. This article examines how Campbell's most ambitious film to date, It for Others (2013), achieves this realignment to produce a measured critique of the commoditization of artworks, and the mythologies that arise in conjunction with their circulation and exhibition.

\section{Documentary Politics}

It for Others is a 54-minute film presented in four chapters. Much of it is narrated by British actress Kate Hardie in a standard English accent using a tone reminiscent of French-Canadian actress Alexandra Stewart's narration in the English-language version of Chris Marker's Sunless (Sans Soleil, 1983). The film most explicitly references Marker and Alain Resnais's controversial critique of the West's colonial appropriation of African art in Statues Also Die (Les statues meurent aussi, 1953) as well as incorporating a vast range of intertexts across various media modes. Ranging from the obscure to the recognizable, the nod to Nicholas Keogh's interactive sound systems constructed from used product packaging is rather esoteric and perhaps mainly recognizable to viewers familiar with localized art scenes in the UK and Ireland [Fig. 1], while similarities to Marker's La jetée (1962), Agnès Varda's Cléo from 5 to 7 (Cléo de 5 à 7, 1962) and Hollis Frampton's (nostalgia) (1971) may be more discernible to the cine-literate. There are also evocations of Bruce Nauman's Beckett-inspired performances to a fixed camera, while the voiceover narration, printed text, and many of the 
originally-filmed sequences are infused with Marxist criticism of the political economy of capitalism. The film's complex transnationality, intermediality and intertextuality facilitate a reimagining of the nature of documentary, particularly at a time when converging media modes and technologies that come packaged in desirable commodity items appear to be causing shifts in perceptions of reality. Such schisms are indicated in Campbell's documentaries when they reflexively expose their own construction in ways that complement the films' socialist politics. Given the fragmentation, repetition and, at times, the disjunction between image and sound in his work, Campbell's approach to documentary film is one which harks back to early documentary's indistinguishability from the modernist avant-garde.

In his important reassessment of the division between avant-garde cinemas and the form of filmmaking John Grierson shaped as documentary in the late 1920s, Bill Nichols explains that documentary's appearance "involves the combination of three preexisting elements - photographic realism, narrative structure, and modernist fragmentation - along with a new emphasis on the rhetoric of social persuasion." While explaining the contentious nature of this combination, he asserts that the element "with the greatest disruptive potential - modernist fragmentation - required the most careful treatment. Grierson was greatly concerned by its linkage to the radical shifts in subjectivity promoted by the European avant-garde and to the radical shifts in political power promoted by the constructivist artists and Soviet filmmakers. He, in short, adapted film's radical potential to far less disturbing ends.” $(2001,582$.$) Due to this concern,$ as documentary developed as a distinct mode of filmmaking, its connections to modernist approaches to film that became aligned with political cinema were increasingly repressed, largely thanks to Grierson's writings and lectures that contributed to their omission from the historical origins of documentary. The socialist impetus of post-war and post-revolution Russian constructivism and Kuleshovian montage certainly jars with the Griersonian documentary form that flourished in Britain in the 1930s. While Esfir Shub, Dziga Vertov and Sergei Eisenstein's films were critical of the bourgeois-serving class system, poetic films such as Industrial Britain (Robert J. Flaherty, 1931) and Night Mail (Harry Watt and Basil Wright, 1936) upheld the status quo in their romantic representations of Britain's otherwise invisible labour. Given the transformative potential of international avant-garde practices, Nichols suggests that Grierson's denial of European and Soviet techniques is part of an urgency in the post-war 1920s and 1930s to affirm the individual's place within national identity and their 
responsibilities to the state. This is certainly a way of evaluating the British documentary movement of the 1930s, which privileged depictions of diligent male workforces and cultural heritage, with notable omissions including the partition of Ireland, shifting regional borders, women's suffrage, migrant communities and growing multiculturalism across the UK.

In addition to cinematic depictions of the workforce, the growing popularity of cinema as an entertainment for workers in the early twentieth century also coincided with the increasing leisure time and expendable income afforded by industrial capitalism. As Peter Burke points out, the very distinction between work time and leisure time that emerged after the Industrial Revolution is itself a product of modernization $(1995,137)$. The modernist avant-garde cinema, however, was too disruptive in its attacks on the viewer to effectively deliver political messages that would reach or be embraced by labourers (for example, Buñuel and Dalí's anarchic yet highbrow Un Chien Andalou [1929] and L'Âge d'Or [1930], the latter of which was famously banned for fifty years). At the same time, the revolutionary potential of fragmentation and juxtaposition in documentary were perhaps undesirable to authorities who required relatively contented, or at least unquestioning, workforces. It follows, then, that celebrating British industries, stoicism and work ethic while maintaining the colonial project in anthropological ethnographies would prevail in Grierson's pioneering documentary movement. It is an interesting development later in the twentieth century and beyond that artist-filmmakers would utilize alternative modes of production and spaces of exhibition to reunite documentary with modernist devices to probe those "disturbing ends" of film's radical potential to intersect with politics - Carolee Schneemann's Viet Flakes (1965) comes to mind. In his re-presentations of history and reality, Campbell tends to adopt an associational style of montage similar to Marker's that refrains from employing the Soviet intellectual montage and is subtler than the Surrealists' more explicit conjunctions. The fluidity of modes, the form, and the complex network of content in It for Others shatters the established body politic of British documentary traditions, and indicates what documentary could yet become as screen cultures continually converge and as artworks with documentary elements become more commonplace in art galleries. ${ }^{1}$

1 It is notable that the work of all four artists nominated for the 2014 Turner Prize, awarded that year to Campbell for It for Others, in some way involved aspects of documentary. This is indicative of a growing trend, certainly in the UK, but also perhaps internationally, as concepts of the real and representations of the real are becoming more and more slippery. 


\section{Intermediality and Intertextuality}

In weaving a vast array of intertexts together in It for Others, Campbell channels Marker's ability "to accommodate the mess" (to borrow from Beckett), which includes original footage in juxtaposition with archival material. The original sequences in Campbell's documentaries tend to be shot in $16 \mathrm{~mm}$, meaning that the similar textures and colour tones can cause difficulties in differentiating Campbell's footage from the archival material (usually of an era when broadcast recordings were filmed on $16 \mathrm{~mm}$ ), particularly when the whole film is digitized and transferred to DVD for exhibition. ${ }^{2}$ This is certainly the case in chapter one, which looks uncannily the same as Statues Also Die, but in fact Campbell re-made the sequence in his studio using replicas, in part due to the British Museum's non-response to a request to film the original artefacts it holds that are similar to those in the Musée de l'Homme. ${ }^{3}$ Imitating Ghislain Cloquet's cinematography, the featured statues are lit and given movement as if they were living beings [Fig. 2]. Together with the extensive use of photographs in chapter four, the film implicitly embarks on an investigation of the relationship between still and moving images, and the nature of time and memory evoked by such objects. The use of film-based media that are digitized to create video art at a time when most commercial films are produced using digital technologies is inherently intermedial. Given the further inclusion of performance to camera, sculpture, commodity items, and superimposed print text into an already busy mixture of film, photographs, television, sound samples and a spoken essay, It for Others is at the very least an intertextual, cross-medial film. While this is true of all films to an extent, It for Others is transparent about it and incorporates this self-awareness into the (self-)criticisms it presents.

The opening sequence establishes the film's Marxist approach to understanding the production, appropriation, circulation, use value, exchange value, and display of objects. Like Sunless, It for Others begins with the voice heard against a black screen, stating: "Objects exist outside of us. It is the confrontation of mind with matter that brings an object into being. Through their use they provide

2 The differences are easier to discern in It for Others than in the earlier Bernadette and Make It New John largely due to the jump in It for Others between widescreen and standard aspect ratios. The distinctions are also indicated when the narrator discusses the filming process and when her comments directly engage with what appears onscreen. Such continued use of $16 \mathrm{~mm}$ in video-making poses an interesting resistance to "new" and "digital" media which until recently pervaded the gallery, but have shifted to the commercial cinema.

3 This claim is made in It for Others and in a promotional video made for the Tate gallery upon the film's nomination for the Turner Prize. 
subsistence, satisfy other human wants, and become the means and processes to produce more objects." The narration immediately echoes chapter 1 of Capital (Marx 1867), which outlines the concept of the commodity and distinctions of valuation. The colonial/globalized scope of the production and exchange of objects with which the film engages becomes clearer as the narration continues: "The wealth of our societies exists as a vast accumulation of objects. This is a film about objects. It refers to another film about objects, specific African objects, a ballad of their mortality and death: Les statues meurent aussi." Before the objects in question are shown, the face of a white man is seen apparently viewing such objects in a museum in a similar way to patrons of the Musée de l'Homme in Statues Also Die [Fig. 3]. However, the frame around his face is cropped into the shape of a vehicle's side-view mirror, thus the art viewer becomes a reframed (and de-/re-centred) object to be scrutinized - and perhaps reflected - by the film's viewers. From the outset there is an indication that acts of seeing and perceiving are as objectified in this film as the objects to which it explicitly draws attention. Indeed, a work's impact can only be measured by monitoring its viewership.

To enable its production, It for Others had to engage in the very acts it and its most explicit referent criticize. For example, during the opening Statues Also Die section, an African-style mask is shown in mid assembly with gesturing hands arranging the precisely cut fragments to be attached to the main block rather than skilfully carved intact [Fig. 4]. Whereas such sequences acknowledge the film's fictions masquerading as truths and reveal the labour that constructed them, it is not always trustworthy as it also makes claims that misdirect the viewer. This is most prominent in the film's iconology of a photograph of IRA volunteer Joseph McCann under analysis later. It for Others also borrows heavily - much more so than from Statues Also Die - from Cléo from 5 to 7, Varda's film about a privileged celebrity embarking on a profound period of self-reflection while awaiting the results of cancer tests. Perhaps conscious of her Left Bank comrades' earlier film, Chapter III of Cléo from 5 to 7 momentarily focuses on replica African masks in two separate shop windows in Paris as Cléo (Corinne Marchand) asks the taxi driver (Lucienne Marchand) to turn the radio off as one of her hit singles plays. When the driver mistakes Cléo's request to stop as an order to stop the car, the camera whip-pans from Cléo to the shop window and quickly cuts to brief close-ups of the masks. Similar sequencing occurs moments later when they are stopped by the flow of traffic. Additionally, a later scene shows Cléo visiting her friend Dorothée (Dorothée Blanck) as she life-models for an art class. Before reaching the session, a tracking shot subjective to Cléo regards several figurative 
clay sculptures placed around shoulder/head-height as she moves through a studio before reaching the class. The spectral presence of this film underpins the issues raised around art production, as well as the stilling of time and the anthropomorphized renderings of humanity in the statues, photographs and commodity items seen throughout It for Others.

Towards the end of the Statues Also Die section, the narration gives way to text overlays, often disappearing too fast to read in full. As a pensive spectator able to pause the film while re-viewing it for study, ${ }^{4}$ I note that the series of statements appearing over pans of the statues point out that establishments like the British Museum in London, whose initial functions were to house "looted art during imperial and colonial rule," can place these objects in their context as "part of universal human history." [Fig. 5.] While in some instances reparations have been made or artefacts repatriated, for the most part, the text states, "the museums also now appear to claim ownership of the cultural patrimony of these objects by enforcing copyright claims." Given the "weak connections" modern nations have with "the culture, spirit, and race of the ancient peoples who produced these objects," the case is made that their return "would be to advance petty nationalism and identity politics; to obscure their true meaning and to close down our understanding of them." The continuing statements point out that if the artworks were to be moved from the central locales of Paris, New York and London, far fewer people could access them, while, on the other hand, Africans are denied "access to these artworks through enforced localization - no Western country will grant an African a visa merely to visit a museum in Europe or America." Where Statues Also Die makes the point that the artworks are displayed in Paris's anthropological "Museum of Man" rather than its home of fine art, the Louvre, Campbell's inclusion of the replicas in It for Others meant they became part of a touring work offine art. When the film was nominated for the 2014 Turner Prize, a prestigious award for young contemporary artists practicing in the UK, the film was shown from October 2014 to January 2015 in London's Tate Britain - a major centre for fine art situated just two miles from the British Museum. Although there remain tensions around ethnographic representation (of which the film is apparently self-critical), the national and cultural claims of ownership discussed in the film contribute to wider concerns around the authorship, ownership and access to cultural products more generally. ${ }^{5}$

4 Warm thanks to Duncan Campbell for giving me access to a digital copy of the film. For more on the pensive spectator and stilling the moving image, see Mulvey (2006).

5 With regards to access, it is worth noting that I viewed It for Others for free when it was shown as part of the Wildscapes exhibition in Belfast's Catalyst Arts in May 2014, but had to pay a $£ 10$ 
The film's second chapter exemplifies the extent of its collaborative authorship. Instead of a voiceover with equations appearing onscreen as might be expected in more traditional expository modes of documentary, the choreographed movements by the Michael Clark Dance Company demonstrate Marx's economic equations from Capital. For example, the sixth of eight movements illustrates measures of value when two of the dancers make an exchange of objects represented by circular mirrors held facing upwards [Fig. 6]. At first one dancer refuses an equal exchange of her one object for one of the other dancer's objects, but then accepts an exchange of her object for both of his objects. The sequence was filmed in black and white $16 \mathrm{~mm}$ in a fixed overhead view. Dressed fully in black, the dancers perform on a white floor, which, given the high camera angle, serves as a backdrop or canvas for the shapes they make with their bodies and props. As seen in movement 6, at times the dancers pull white textile sheets across the floor (the manufacture of which in China is indicated towards the end of the film in another example of its self-awareness as a product of global neoliberal capitalism), and their unfurling reveals the partially printed equations completed by the dancers and objects. Without reflexively revealing the arrangement of the printed sheets onscreen, the viewer could easily assume that the text was added in post-production, such is the flattening effect of the overhead wide angle and grainy texture when stilled. Michael Clark's off-camera directions to the five dancers are also heard on the audio track, as are the dancer's footsteps and the scraping sounds they make as they slide themselves and other objects across the floor.

The adaptation of text into a studio performance delivered to camera evokes North American artist Bruce Nauman's performance-to-camera works such as Slow Angle Walk (Beckett Walk) (1968), in which he enacts an arduous series of actions derived from passages in Samuel Beckett's plays and prose. In a similar way to Nauman's, the performances in It for Others often extend beyond the frame while the shouted directions and sounds of movement continue. This is where the distinction between documented performance art and performancebased video and photography as identified by Philip Auslander (2006) becomes complex. Like Nauman's, this private pre-arranged studio performance was designed to be filmed. While the camera is observational and at a distance, the pre-arranged text onscreen using the printed sheets together with the planned performances are a conceptualization of the documentary device of re-enactment.

entry fee (on top of travel to London) to see the Turner Prize exhibition, such is the prestige of the event. It is also important to bear in mind that even when it is freely accessible, there does remain a knowing disconnect between modern/modernist art and the average consumer of cultural products. 
In this instance, it converges with the expositional conceptualization of the issues Marx examines in Capital. In this sequence, documentary filmmaking, performance-to-camera, contemporary dance, printed textiles, and adaptation all converge as one, while the modernist repetition and use of figurative shapes effectively outline without direct quotation Marx's discourse on the emergence and growth of systems of commerce, and his criticism of the disjunction between an object's use value and exchange value. Following the conceptual description of Marx's equations, chapter 3 ruminates on the commodified object, and the commoditization of the labour it takes to make commodified objects. The narration is illustrated by hand performances depicting a white North American (indicated by the narrator and the brands of cigarettes and products they use) working class heterosexual couple at a dining table. This is intercut with studio shots and excerpts of television advertisements for a range of international products presented in anthropomorphic packaging - the montages of which are timed to the jazz drumming from Statues Also Die. The socialist message pervades the mise-en-scène in their various sequences: a red tablecloth, The Socialist Worker mock-up newspaper, the woman's red nail varnish, and an array of red foodstuffs including Campbell's tomato soup [Fig. 7]. A further cutaway from the domestic table involves the red-nailed hand repeatedly setting down the soup tin against a white backdrop [Fig. 8]. Notably, the shots were re-filmed rather than looped, acknowledging Andy Warhol's individually screen-printed Campbell's Soup Cans (1962), as well as referencing Campbell himself in a way that reflects his methods in practice and the tension between authorship and mass re/production.

The fourth and final chapter of It for Others is titled "Reflexes." It is the only section to be demarcated as such, and begins not long after the voiceover talks through the film's process of being shaped into an inquisitive narrative to be presented in "four or five chapters." The title appears over a close-up of the scattered contents of a purse, including the broken shards of a mirror, dropped on tarmac [Fig. 9]. This is a contemporary reconstruction (denoted by the use of Euro notes instead of Francs) of the "Chapitre XI: CLÉO de 18 h. 04 à 18 h. 12" section breaker in Cléo from 5 to 7 when Cléo drops her purse. As Dorothée helps retrieve the items she remarks that the broken mirror is an omen of death. The inclusion of this visual reference continues Campbell's device of re-filming, and thereby reiterating and recirculating, extant works with connections to the modernist avant-garde, while also identifying links between texts otherwise not immediately relatable to one another. The shot also spectrally calls to mind the symbolic shattering of a character who initially embodies shallow consumerism 
in her long-winded purchase of a winter hat in midsummer - an item which brings her momentary pleasure that she soon forgets about and cannot wear for long due to the heat. Cléo's desire for the hat early in the film symbolizes the absurd natural conclusion of an item's use value; it is what consumers are told to desire whether or not it is fit for purpose and provides a fair exchange value. It for Others is imbued with Cléo's growing self-awareness and her questioning of what in life brings real fulfilment beyond the constructed desirability of commodity items. Yet her journey is shaped by constant encounters with death omens that negate her sense of the future.

It for Others ends where Cléo from 5 to 7 begins. The closing credits appear over an almost shot-for-shot black and white homage to Cléo's tarot reading in what is the only colour sequence in Varda's film [Fig. 10]. Similar to the earlier overhead shots, the sequence imitates the high angle with the lightshade making a semi-circle to the right of the frame as the older pair of hands deals the cards and beckons to the younger pair to make a selection. ${ }^{6}$ Tarot raises further issues around the authorship of histories and predetermination of the future. The cards present another visual medium that produces narratives told in image sequences that beg interpretation, like a series of photographs. When played for the purposes of divination, tarot operates on the possibility that life's pathways preexist and can be deciphered. The cards are chosen by the person being read, and interpreted by the reader. The reading is not set in stone, but rather is usually the description of possible outcomes that rely on the paths chosen by the individual but can also be determined by encounters with others. The paths we take are contingent on many factors; there is no one identifiable author of any life. The information to which the viewer is privy regarding Cléo's fate at the start of the film contrasts what she learns at its close, and neither outcome is necessarily what will transpire. The film is a slice of time, a compressed linear two hours of a character's life, which, like the momentary duration of a photograph, extends into the past and the future.

The apex of the arguments in It for Others comes in another visual omen of early death, namely the photograph of Joe McCann. Leading up to its presence onscreen is a series of photo cards held in front of the static camera. The sequence consists of a long static close-up of hands holding the photos and placing the top one to the back (that is, recirculating them) in time with a narrative of connected

6 The credit sequences are also similar, with Campbell adopting the same typeface as that used in Cléo from 5 to 7 throughout It for Others and presenting the first names in lowercase with the surnames in uppercase. 
memories delivered by a different, more personal, voiceover. In an American accent, a woman reads short letters to Freda, presumably the speaker, sent by Alan, who seems to be a friend. As well as similarities in the form, the sequence contains references to Marker's La jetée [Fig. 11]and Frampton's (nostalgia), both of which engage with memory and the photographic image. Hardie's narration returns and the series of photographs ends on McCann's - an image the film uses to analyse the commoditization of the photographic object, and the subsequent commoditization of the mythologized martyred figure it depicts [Fig. 12].

\section{Re-presenting History}

The photograph of a silhouetted figure holding a gun and kneeling under a flag remains onscreen in silence for a few moments, allowing time for contemplation. The year 1972 appears onscreen over the hands holding the photo card. The narrator explains: "This photograph was taken by Ciaran Donnelly. On the 10th of August, a group of six official IRA volunteers led by Joseph McCann took over Inglis's Eliza Street Bakery in the markets area of Belfast. During the incident, the photographer captured the profile of McCann in silhouette, hunkered down, an M1 Carbine resting on his knee, a Starry Plough flag fluttering above him. It is an image so dramatic and so visually striking that it seems almost composed. [...] Mistaking the flag, the American correspondent Jordan Bonfante wrote: 'Beneath the Irish Republican tricolour, Joe awaits a counterattack by British infantry during the battle of Eliza Street. Joe was a tall, thin man who moved only in leaps and crouches'." Here the commentary raises issues concerning "the mythology of content and intent" that mark tensions between art and the telling of history. Whether the flag was genuinely mistaken by Bonfante or not, the reference to the Irish tricolour clearly signifies nationalist/Republican political struggles against British colonialism in Ireland, whereas references to the Starry Plough may need more specialist knowledge and explanation to successfully convey the relevant sense of identity and cause. Reduced and romanticized at the same remove, McCann's appearance in this much-reproduced image presents him as a dynamic revolutionary. The photograph became a memento mori of McCann, and for the same Irish Republican movement that ceased fire in 1994 and became fundamental to the Northern Ireland peace process. This unplanned image, or rather, its legacy, has preserved memories of McCann while appropriations of it have transformed

$7 \quad$ Much of this commentary was appropriated and paraphrased from John Mulqueen and Jim Smyth's 2010 History Ireland article. 
him into a commodity. In doing so, this image and its derivatives precariously straddle the fissures between history and art, and reality and mythology.

For what is perhaps the only time in It for Others, Hardie's voiceover takes a first-person stance in claiming not to agree that "the use of appropriation, irony, or cropping gets us any closer to a consideration of the original use or exchange values. The implicit critique is overwhelmed by the power of the original image." This is troubled, however, when the original image is replaced in popular memory by subsequent versions, as is largely the case with the famous Che Guevara poster designed by Jim Fitzpatrick, to which the voiceover soon alludes. Just as the romantic silhouette of McCann looks staged and has been easily appropriated, Alberto Korda's original photograph of Guevara was easily altered to transform the socialist revolutionary into a confident and powerful icon for all leftist political movements. The poster has instead been widely traded on the free market, and its meaning diluted. In telling its version of the narrative of the McCann photo, It for Others parodies these specific commercial appropriations of uncopyrighted images by stating - and showing - that prints of the photo headed with "RESISTANCE" appeared on a range of Christmas stockings. What better than a reference to a commercialized religious festival to concisely satirize the commoditization of histories and martyred figures? Fitzpatrick did in fact produce a poster of McCann bearing similarities to the Guevara poster that is now iconic in popular culture, but it was not rendered from one of Donnelly's photographs. ${ }^{8}$ The silhouette of McCann with gun and flag, however, does appear on commercially available merchandise as well as anonymously made posters. As the narrator states while the photograph is onscreen, "art activity as it becomes useful, even to the extent of entering culture, becomes no longer art, but history, history being perhaps the most viable tool of differential political power.” The narrative the film constructs around this photograph is the process of art not only becoming history, but of rewriting history, and in doing so, it produces a different political, indeed a different kind of socialist message regarding ownership and authority. With knowing irony, the film is subject to its own criticisms.

The hands holding the photograph of McCann retract leaving the tablecloth filling the frame for several beats before cutting to archival colour news footage. As children point out the bullet holes in a wall, the voiceover describes the official account of "the manner of his death: shot ten times by British paratroopers while lying unarmed and wounded on the pavement in April 1972." The interior and

8 As Mulqueen and Smyth (2010) point out, two were taken in quick succession bearing minor differences. Both have been used for different posters and magazine covers. 
exterior shots revealing more bullet holes are intercut with extensive footage of a populated funeral procession. It is clear that it is a Republican funeral taking place in Belfast (against the backdrop of Black Mountain to the north of the city at times in frame) but, interestingly, there are no clear indicators identifying it specifically as McCann's. Furthermore, the sequence has been edited in such a way as to make the depicted events cohere as one. While they likely are from McCann's funeral, which by all recorded accounts was a substantial affair, the sequence resembles so many similar recordings of paramilitary funerals from the same era that they are rendered generic and interchangeable. The narrator alludes to this, stating that "since the 1790s, large stage-managed funerals as political demonstrations have been a staple of Republican mobilization." The individual is immaterial as the funeral fronts a public demonstration for the cause, which in the process martyrizes the person being buried. In this scenario, the surviving images of subjects like McCann become signs of resistance at all costs. But, "resistance to what?"

The voiceover discusses the failure of the Irish Republican movement, drawing attention to issues of class and human rights which became masked and forgotten once the upheaval turned sectarian by the beginning of the 1970s. The movement, the narrator observes, became distracted by interior territorialism that gave rise to hierarchies of power and control amongst groups and communities. There is a suggestion that this is also true of the political economy of the art world and globalized industries. Original use values have been forgotten. More than forty years after McCann's death, and nearly twenty since a devolved power-sharing government was established in Northern Ireland, the images of him that continue to circulate represent a cause that is economically, socially and politically not currently viable. In an essayistic fashion, the film uses this point to make another: "If you take this representation of Chinese textile workers as an epitome of the international division of labour, in forty years' time, what will its function be?" The observational documentary footage (which appears to have been shot in high-definition digital rather than $16 \mathrm{~mm}$ film) consists of wide angle shots and pans of large, busy factory floors, stacked warehouses, operatives working at large machines (processing long white sheets), and workers exiting the factory at shift's end. The self-conscious admission that this representation has been included, not to ethnographically document Chinese labour making items for export, but to make a socialist point about the international political economy and commodity exchange, again calls attention to the film's self-awareness as a circulating art object. Not only has its production relied on the substantial appropriation of other objects, it too is an object that could in time be carved up and re-appropriated. 


\section{Self-Reflection}

The film's self-awareness persists as it comes under its own interrogation: "And what about this film? Is it possible to take its anti-commercial self-representations at face value, to appreciate it in a social vacuum, to ignore the context that is shown?" It for Others is primarily a video installation; it is a work that while exhibited will be replayed countless times and will only be viewed in part by most gallery visitors. It is not available to buy or for public view online. It cannot be rewatched by general viewers once the exhibitions close. With knowledge of later events such as the Turner Prize award, and research into the film's intertextual references, only some of which are examined here, this article shows that the film's "anti-commercial self-representations," in addition to the range of contexts it evokes, beg critical interrogation, and know it. The film recognizes that it has a figurative shelf life, but perhaps it also foresees its mummified preservation and recirculation in reviews and scholarly analysis, just as it has done with the statue replicas, photographs, archival footage, textual references and sound samples that contribute to its genetic makeup.

To expand a little on my vague reference to Bazin's comparison of photography to mummification, It for Others is pervaded by notions of death which are synonymous with acts of preservation. The final instance of this occurs when the voiceover's detailed closing discussion of the art market is juxtaposed with the tarot's death omen. In speculating on its value, the voiceover asserts that "a key factor in pricing this film would be its length in minutes," suggesting that longevity in art equates value. Durational - that is, limited - time is also evoked by the contents of the final four trump cards including the Hanged Man and Death which match the four cards that predict Cléo's untimely death at the beginning of Cléo from 5 to 7 . In particular, the final images, now in colour, copy the extreme close-ups of the Death card, notably the bottom depicting Death's scythe cutting off the heads of those he stands upon (symbolizing life cut short [Farley 2009, 76]), and the top revealing the skeletal representation of death before the frame cuts to black. Of course, drawing the Death card can also indicate renewal, an end giving way to a beginning, which is also ambivalently suggested at the end of Varda's film. Indeed, "making it new" lies at the core of the broader modernist project. What this complex work indicates for the future of visual art, documentary film and cinema is that while the old apparatus may no longer be turning reels, new means and modes of preservation and circulation are in full spiral. Survival means accepting death. The cinema is dead. Long live the cinema. 


\section{References}

Auslander, Philip. 2006. The Performativity of Performance Documentation. Performance Art Journal no. 84: 1-10.

Bazin, André. 1960. The Ontology of the Photographic Image. Film Quarterly vol. 13 no. 4 (Summer): 4-9.

Burke, Peter. 1995. The Invention of Leisure in Early Modern Europe. Past \& Present no. 146 (February): 136-150.

Farley, Helen. 2009. A Cultural History of Tarot: From Entertainment to Esotericism. London; New York: I.B. Tauris.

Marx, Karl. 1976 [1867]. Capital: A Critique of Political Economy. New York: Penguin Books.

Mulqueen, John and Jim Smyth. 2010. "The Che Guevara of the IRA:” The Legend of "Big Joe” McCann. History Ireland vol. 18 no. 1 (January/February): 46-47.

Mulvey, Laura. 2006. Death 24x a Second: Stillness and the Moving Image. London: Reaktion Books.

Nichols, Bill. 2001. Documentary Film and the Modernist Avant-Garde. Critical Inquiry vol. 27 no. 4 (Summer): 580-610. 


\section{List of Figures}

Figure 1. A radio made from garbage in It for Others (Duncan Campbell, 2013). Note the depiction of the hand's labour with the product. Figure 2. Re-filming Statues Also Die (Chris Marker and Alain Resnais, 1953).
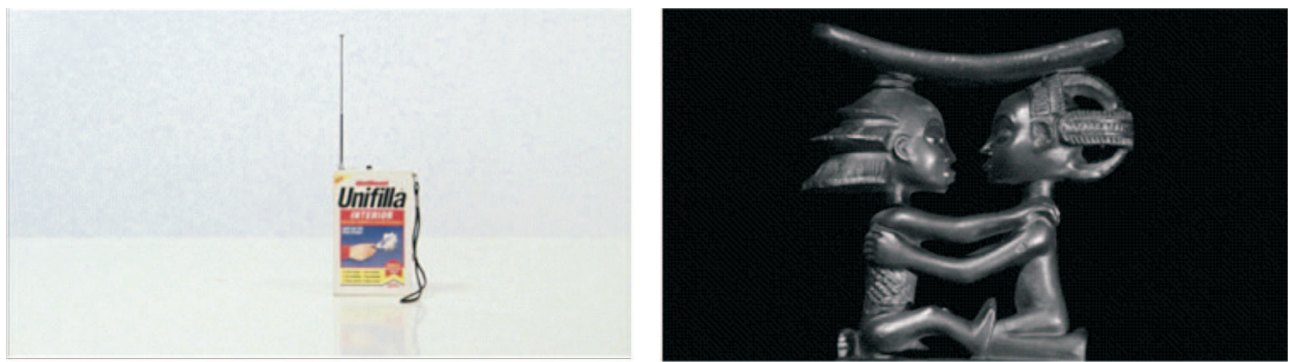

Figure 3. Turning the gaze onto the spectator. Figure 4. Constructing a replica African mask.
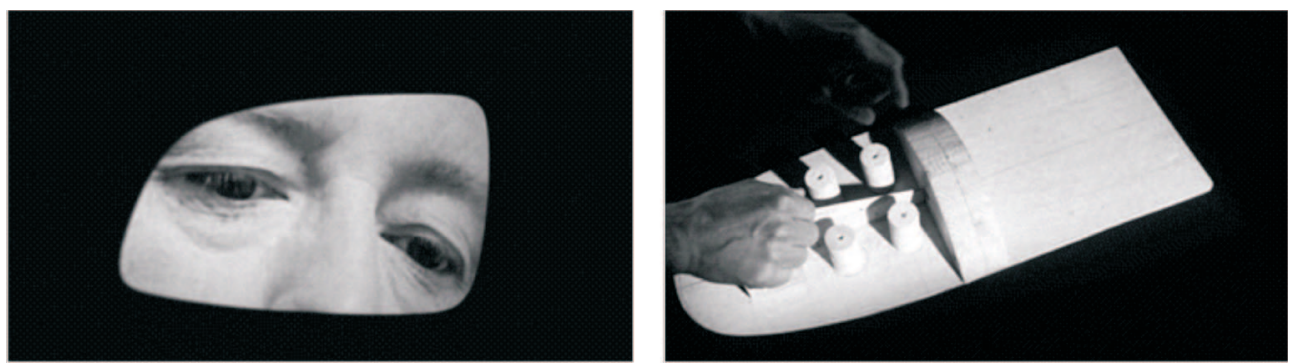

Figure 5. Reviving the criticism of colonial appropriation and claims of ownership over cultural artefacts. Figure 6. Demonstration of exchange value by the Michael Clark Dance Company.
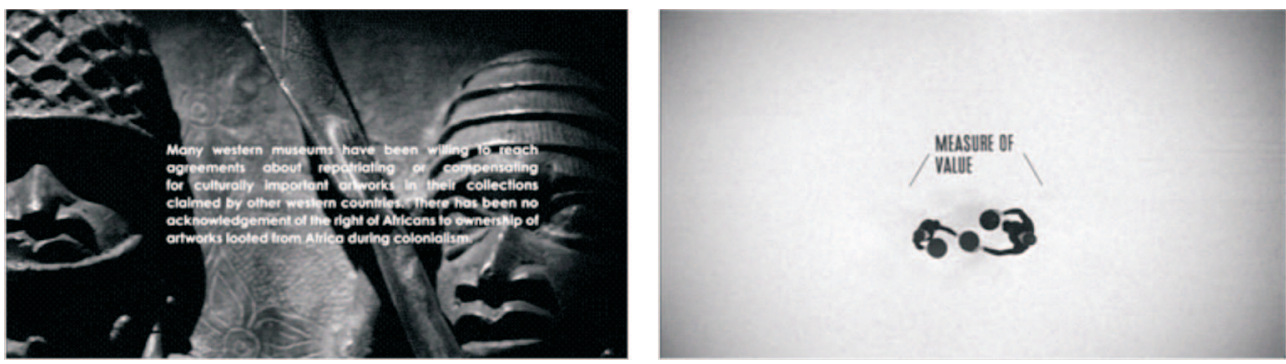
Figure 7. Socialist reds in the domestic setting in It for Others. Note the photographs on the table, particularly the nod to Marker's La Jetée (1962). Figure 8. Campbell's Tomato Soup.
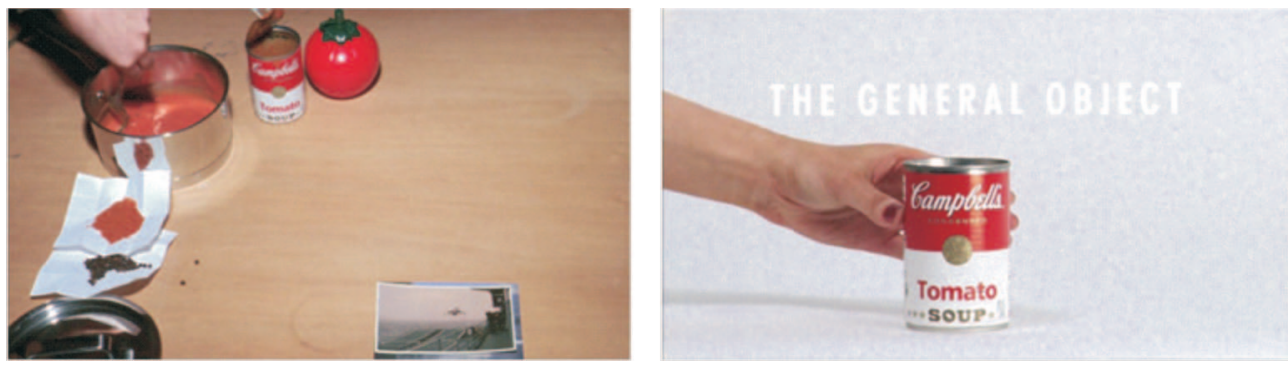

Figures 9-10. Referencing the chapter markers from Cléo from 5 to 7 (Agnès Varda, 1962) and a remake of Cléo's tarot reading from Varda's film.
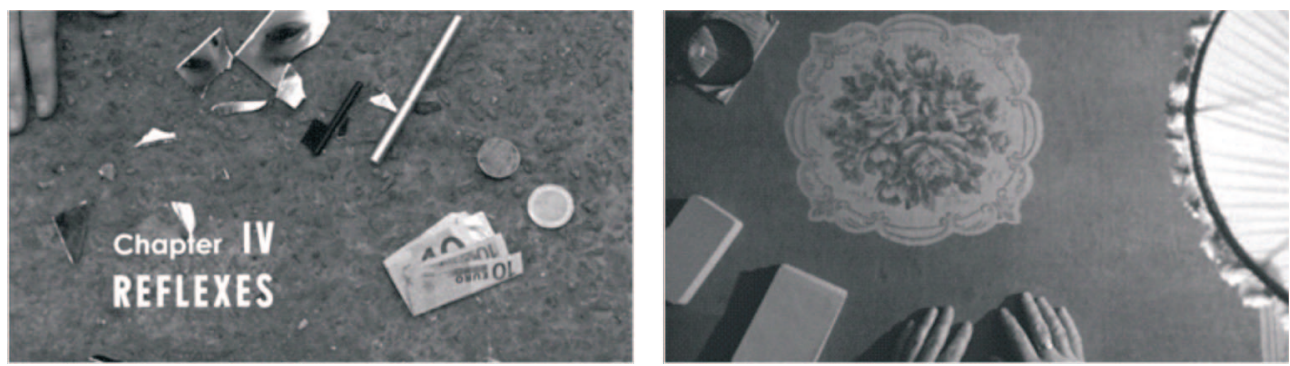

Figures 11-12. Reference to La jetée (Chris Marker, 1962) and Ciaran Donnelly's photograph of Joseph "Big Joe” McCann.
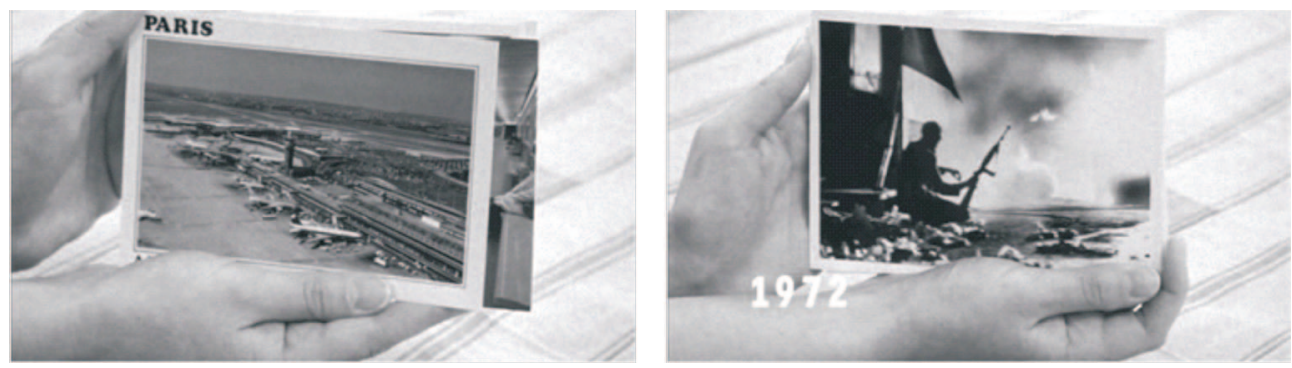